AperTO - Archivio Istituzionale Open Access dell'Università di Torino

\title{
Diazoxide postconditioning induces mitochondrial protein S-Nitrosylation and a redox-sensitive mitochondrial phosphorylation/translocation of RISK elements:no role for SAFE
}

\section{This is a pre print version of the following article:}

Original Citation:

Availability:

This version is available http://hdl.handle.net/2318/138647

since

Published version:

DOI:10.1007/s00395-013-0371-z

Terms of use:

Open Access

Anyone can freely access the full text of works made available as "Open Access". Works made available under a Creative Commons license can be used according to the terms and conditions of said license. Use of all other works requires consent of the right holder (author or publisher) if not exempted from copyright protection by the applicable law. 


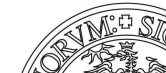 \\ UNIVERSITÀ DEGLI STUDI DI TORINO}

The final publication is available at Springer via http://dx.doi.org/10.1007/s00395-013-0371-z

Penna C, Perrelli MG, Tullio F, Angotti C, Camporeale A, Poli V, Pagliaro P. Diazoxide postconditioning induces mitochondrial protein $\mathrm{S}$-Nitrosylation and a redox-sensitive mitochondrial phosphorylation/translocation of RISK elements: no role for SAFE. Basic Res Cardiol. 2013 Sep;108(5):371. 
Diazoxide Postconditioning Induces Mitochondrial Protein S-Nitrosylation and a Redox-Sensitive Mitochondrial Phosphorylation/Translocation of RISK Elements: no Role for SAFE

Penna $C^{1^{*}}$, Perrelli $M-G^{1^{*}}$, Tullio $F^{l}$, Angotti $C^{l}$, Camporeale $A^{2}$, Poli $V^{2}$, Pagliaro $P^{l}$

Università di Torino, ${ }^{1}$ Dipartimento di Scienze Cliniche e Biologiche and ${ }^{2}$ Dipartimento di Biotecnologie Molecolari e Scienze della Vita, Italy

* These two authors contributed equally to this work.

Corresponding Author:

PasqualePagliaro

Dipartimento di Scienze Cliniche e Biologiche

Facoltà di Medicina e Chirurgia "S. Luigi Gonzaga"

Regione Gonzole 10

10043 Orbassano (TO), Italy.

Phone: +39011670.5450

Fax: +390119038639

e-mail: pasquale.pagliaro@unito.it 


\section{Abstract}

Postconditioning (PostC) can be obtained either with brief cycles of ischemia/reperfusion (IPostC) or with a direct targeting of mitochondria with Diazoxide (pharmacological PostC, PPostC). I-PostC may induce the activation of RISK and SAFE pathways and may favor nitric oxide production with S-Nitrosylation of proteins and redox signaling. It is not clear whether Diazoxide can lead to similar effects. We compared the effects of I-PostC and P-PostC on a) kinases of RISK- and SAFE-pathway, b) S-Nitrosylation of mitochondrial proteins and $c$ ) reduction of death signals (PKC $\delta$, cleaved-caspase 3 and Beclin-1) in cytosolic and mitochondrial fractions. Isolated rat hearts, underwent 1) perfusion without ischemia (Sham), 2) ischemia/reperfusion (30-min ischemia plus 2-hours reperfusion), 3) I-PostC (5 intermittent cycles of 10-s reperfusion and 10-s ischemia immediately after the 30-min ischemia), 4) P-PostC (Diazoxide $30 \mu \mathrm{M}$ in the first of 3-min of reperfusion) or 5) I-PostC+MPG or P-PostC+MPG (MPG, 2-mercaptopropionylglycine $300 \mu \mathrm{M}$ ). Using Western blot and biotin switch assay, we found that P-PostC induced a redox sensible phosphorylation/translocation of Akt, ERK1/2 and GSK3 $\beta$ into the mitochondria, but not of phospho-STAT3, which was translocated into the mitochondria by I-PostC only. Either I-PostC or P-PostC increased mitochondrial S-Nitrosylated proteins (e.g., VDAC) and reduced the levels of phospho-PKC $\delta$, cleaved-caspase3 and Beclin-1. Therefore, direct targeting of mitochondria with Diazoxide $a$ ) activates the RISK-pathway via a redox signaling, $b$ ) favors discrete mitochondrial protein S-Nitrosylation, including VDAC and $c$ ) decreases signals of death. Intriguingly, phospho-STAT3 translocation is induced by I-PostC, but not by P-PostC, thus suggesting a redox-independent mechanism in the SAFE-pathway.

Key words: Cardioprotection; Ischemia; Nitric oxide; Reperfusion; RISK; SAFE. 


\section{Introduction}

Reperfusion is the only way to salvage an ischemic organ, but it is a double-edged sword and can induce severe and irreversible damages to the myocardium, collectively referred to as reperfusion injury $[42,76,88]$. Cycles of brief reperfusion and ischemia performed immediately at the onset of reperfusion following a prolonged ischemic insult markedly limits reperfusion injury. This cardioprotective phenomenon is named Ischemic Postconditioning (I-PostC), which is as powerful as ischemic preconditioning [89]. I-PostC may limit all forms of cell death induced by ischemia and reperfusion (I/R) $[20,21,41,44,72]$.

It is known that I-PostC induces the activation of Reperfusion Injury Salvage Kinase (RISK) and Survivor Activating Factor Enhancement (SAFE) pathways [33,34,40,75], with a potential dependence of signaling on species and models $[77,78]$. While the SAFE pathway recognizes STAT3 activation as a central point, the RISK pathway includes the activation/phosphorylation of several kinases (e.g., Akt, ERK1/2, GSK3ß) [33,34,79]. Nevertheless, both pathways converge on mitochondria influencing their function. In particular, in the mitochondria, cardioprotective pathways lead to the opening of mitochondrial $\mathrm{K}_{\mathrm{ATP}}$ dependent (mitoK $\mathrm{K}_{\mathrm{ATP}}$ ) and closure of mitochondrial transition pore (mPTP) with consequent integrity of these organelles $[9,35,67,70]$. mitoK $_{\text {ATP }}$ channel activation may be involved in the production of small quantity of reactive oxygen species (ROS), which helps to preserve integrity and proper functioning of mitochondria themselves $[1,14,24,62,66,70]$. In fact, like preconditioning, PostC depends on ROS signaling $[25,69,84]$. The I-PostC maneuvers also induce the production of nitric oxide (NO) and reactive nitrogen species (RNS) [69], which can lead to mitochondrial proteins S-Nitrosylation (SNO) [25,68,80-83]. Then ROS/RNS in turn lead to the activation of survival kinases such as MAP kinases, tyrosine kinases and PKCs, including $\mathrm{PKC} \varepsilon$ and $\mathrm{PKC} \delta$, which may have opposing roles $[12,15,16,31,36,45,58,62]$. 
Therefore cardioprotective stimuli starting from outside the mitochondria converge on these organelles and then reverberate in the cytosol again. Specifically, I-PostC leads to the translocation/phosphorylation of effectors of the RISK and SAFE pathways to the mitochondria, then signals from mitochondria affects cytosolic elements again [7,19,33,34,62,66].

A protection similar to that obtained with I-PostC has been obtained with pharmacological agents given in early reperfusion, referred to as Pharmacological PostC (P-PostC). Many of these pharmacological treatments target directly mitochondria $[17,33,46]$. Recently, we have demonstrated that the infusion of Diazoxide, a direct and selective opener of mitoK $\mathrm{ATP}_{\mathrm{AT}}$ channels, induces cardioprotection when infused in the initial three min of reperfusion [65]. Diazoxide mediated cardioprotection requires a ROS signaling, both in ischemic pre- and post-conditioning $[27,65]$. Most notable, preconditioning with Diazoxide can increase NO bioavailability [4] and protein translocation $[4,27,51]$.

Therefore, we hypothesized that P-PostC with Diazoxide includes SNO-proteins and a ROS signaling that triggers a cross talk between mitochondria and cytosol, with consequent translocation of cardioprotective factors from cytosol to mitochondria.

Also when the ischemic heart is reperfused in the absence of any cardioprotective maneuvers, a cross-talk between cytosol and mitochondria is responsible for the activation of several mechanisms which favor the development of "signals of death" leading to oncosis, apoptosis and/or autophagy $[54,64,66]$. Among these, a role is played by PKC $\delta$ translocation within mitochondria, where it induces several metabolic modifications, increases mitochondrial ROSstress, and promotes apoptosis [16]. Importantly, both I-PostC and some P-PostC reduce some of these signals of death $[67,81]$. To the best of our knowledge there are no studies on the effects of P-PostC with Diazoxide on signals of death. 
Our study was aimed to compare the effects of two different types of postconditioning (I-PostC and P-PostC, which target indirectly and directly mitochondria, respectively) in terms of 1) kinase phosphorylation and translocation, 2) amount of nitrosylated proteins, and 3) modification of "signals of death" in mitochondrial fractions obtained from reperfused hearts. 


\section{Materials and Methods}

Animals

Male Wistar rats (5-6 month old, body weight 450-550 g) were purchased from Janvier (Le Genest-St-Isle, France). Animals received humane care in compliance with Italian law (DL-116, Jan. 27, 1992) and in accordance with the Guide for the Care and Use of Laboratory Animals published by the US National Institutes of Health (NIH Publication No. 85-23, revised 1996).

Perfusion technique

Methods used were similar to those previously described [61,63,65,69]. In brief, isolated rat hearts were retrogradely perfused at constant flow $(9 \pm 1 \mathrm{ml} / \mathrm{min} / \mathrm{g})$ with oxygenated KrebsHenseleit buffer $(127 \mathrm{mM} \mathrm{NaCl}, 17.7 \mathrm{mM} \mathrm{NaHCO}$, $5.1 \mathrm{mM} \mathrm{KCl}, 1.5 \mathrm{mM} \mathrm{CaCl}, 1.26 \mathrm{mM}$ $\mathrm{MgCl}_{2}, 11 \mathrm{mM}$ D-glucose (Sigma-Aldrich, St. Louis, MO, USA) gassed with 95\% $\mathrm{O}_{2}$ and $5 \%$ $\mathrm{CO}_{2}[61,63,65,69]$. Hearts were paced at $280 \mathrm{bpm}$ and kept in a temperature-controlled chamber $\left(37^{\circ} \mathrm{C}\right)$. Coronary perfusion pressure and left ventricular pressure were monitored to assess the preparation conditions.

\section{Experimental protocols}

\section{Infarct size groups}

After the stabilization period, hearts were randomly divided in three groups ( $\mathrm{n}=6$ for each group): 1) I/R group, hearts underwent 30-min of global ischemia and then a period of 120-min full reperfusion; 2) I-PostC group, after 30-min ischemia, hearts underwent a PostC protocol (5 cycles of 10-s reperfusion and 10-s global ischemia) then a period of 120-min full reperfusion [63,65,69]; 3) P-PostC group, after 30-min ischemia, hearts were infused with Diazoxide (30 $\mu \mathrm{M})$ $[27,32,65]$ for 3-min and then underwent a period of 120-min full reperfusion.

In two additional groups of hearts (P-PostC+MPG and I-PostC+MPG; $n=5$ for each group), the mitochondrial specific antioxidant, 2-mercaptopropionylglycine (MPG, $300 \mu \mathrm{M}$ ), was co-infused 
with Diazoxide (30 $\mu \mathrm{M})$ or during I-PostC maneuvers, in the initial 3-min of 120-min reperfusion, in order to verify the role of redox signaling [27,65 and references therein].

Assessment of myocardial injury

Infarct areas were assessed at the end of the experiments with the nitro-blu-tetrazolium technique (Sigma-Aldrich, St. Louis, MO, USA) in a blinded fashion, as previously described $[61,63,65,69]$. In brief, immediately after reperfusion hearts were rapidly removed from the perfusion apparatus and the left ventricle dissected into $2-3 \mathrm{~mm}$ circumferential slices. Following 20-min of incubation at $37^{\circ} \mathrm{C}$ in $0.1 \%$ solution of nitro-blue tetrazolium in phosphate buffer, unstained necrotic tissue was carefully separated from stained viable tissue by an independent observer, who was unaware of the protocols. The necrotic mass was expressed as a percentage of risk area (i.e., total left ventricular mass).

\section{Western blotting and S-Nitrosylation}

Isolation of rat heart mitochondria

Seven additional groups of hearts were used to separate the mitochondrial and cytosolic fractions: five experimental groups ( $n=6$ for each Group) are similar to those used for the evaluation of infarct size; the other two groups are 1) a Sham (non-ischemic) group in which hearts underwent 80-min buffer-perfusion only ( $\mathrm{n}=6$; Sham group) and 2) a non-ischemic group, in which, for comparative purpose, Diazoxide (DZO) was infused for 3-min after the stabilization period $(n=4$; Sham+DZO group). Mitochondrial and cytosolic fractions were obtained by a modification of published procedures $[3,10]$. In brief, the left ventricle was quickly submerged in $250 \mathrm{mM}$ mannitol, $0.5 \mathrm{mM}$ EGTA, $5 \mathrm{mM}$ HEPES, and $0.1 \%(\mathrm{w} / \mathrm{v})$ BSA (pH 7.4). The tissue was finely minced with scissors and then homogenized in the same buffer (10 $\mathrm{ml}$ buffer per $\mathrm{g}$ tissue), using an ice-cold Potter. Large cell debris (membrane and nuclear fractions) were pelleted by centrifuging the homogenate twice for 5-min at $600 \mathrm{~g}$ and discarded avoiding solubilization of 
membrane proteins. Mitochondria were pelleted by 10 -min centrifugation at $10,300 \mathrm{~g}$. The supernatant was centrifuged for $1 \mathrm{~h}$ at 100,000 g to obtain cytosolic fraction. The mitochondrial pellet was suspended, loaded in tubes containing 30\% (v/v) Percoll in $225 \mathrm{mM}$ mannitol, $1 \mathrm{mM}$ EGTA, $25 \mathrm{mM}$ HEPES, $0.1 \%(\mathrm{w} / \mathrm{v}) \mathrm{BSA}(\mathrm{pH} 7.4)$ and spun for 30-min at 95,000 $\mathrm{g}$ in a Beckman Coulter centrifuge with SW40 rotor. Mitochondria were collected from the lower part of the dense, brownish yellow mitochondrial band [67]. Protein level in each fraction was determined by Bradford's method [11].

\section{Western blotting}

About $50 \mu \mathrm{g}$ of protein extracts were separated by SDS-PAGE on $8 \%$ [for $\mathrm{Na}^{+} / \mathrm{K}^{+}$ATPase, PKC $\delta$, phospho-PKC $\delta$, STAT3, phospho-STAT3, vinculin, mitochondrial trifunctional enzyme $\alpha$ subunit (HADHA)] 10\% [for HSP60, voltage-dependent anion-selective channel (VDAC), protein disulfide isomerase (PDI), Lamin A/C, Akt, phospho-Akt, GSK3 $\beta$, phospho-GSK3 $\beta$, Beclin-1] or 12\% [for Phospholamban (PLN) and cleaved caspase-3] gels and transferred to PVDF membrane (GE Healthcare, Buckinghamshire, UK). The membranes were incubated overnight with the following primary antibodies: anti- $\mathrm{Na}^{+} / \mathrm{K}^{+}$ATPase $\alpha 1$ (Upstate Biotechnology, Billerica, MA, USA ), anti ERK1/2, anti-phospho-(Thr-202/Tyr-204)-ERK1/2; anti-PKC , anti-phospho-(Ser-

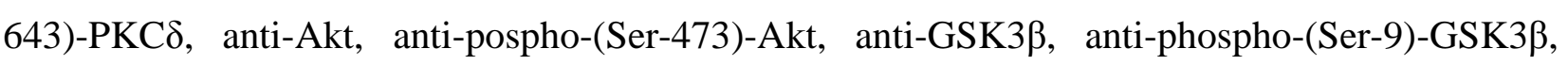
anti-cleaved-caspase-3, anti-phospho-(Ser-727)-STAT3, anti-phospho-(Tyr-705)-STAT3 (Cell Signaling Technology, Beverly, MA, USA), anti-Beclin-1 (Sigma-Aldrich, St. Louis, MO, USA), anti-HSP60 (BD Biosciences, Franklin Lakes, NJ, USA), anti-Lamin A/C and anti-PLN (Santa Cruz Biotechnology, Santa Cruz, CA, U.S.A.), anti-VDAC and anti-PDI (Abcam, Cambridge, UK) all were diluted according to the manufacturer's instructions. Immunoblotted proteins were visualized by using Immuno-Star HRP Substrate Kit (Bio-Rad Laboratories, Hercules, CA, USA) and quantified by Kodak Image Station 440CF. To confirm equal protein loading, blots were 
stripped with $0.4 \mathrm{M} \mathrm{NaOH}$ and then re-blotted for all antibodies as well as for anti-vinculin antibody (Sigma-Aldrich, St. Louis, MO, USA) or for anti-HADHA (Abcam, Cambridge, UK) for cytosolic and mitochondrial fractions, respectively. Image analyses were performed by the Kodak 1D 3.5 software [67].

Biotin switch assay for the detection of S-Nitrosylated proteins

All preparative procedures were performed in the dark (covering all equipments with aluminum foil) to prevent light-induced cleavage of nitrosylations $[2,47,68,82,86]$. Mitochondrial fractions were incubated and centrifuged on ice in appropriate buffers $\left(20 \mathrm{mmol}^{-1}\right.$ Tris $\mathrm{pH} 7.5,150 \mathrm{mmol}$ $\mathrm{l}^{-1} \mathrm{NaCl}, 1 \%$ Igepal CA 630, 0.5\% Sodium Deoxycholate, 1 mmol $\mathrm{l}^{-1}$ EDTA, 0.1\% SDS, 200 mmol $~^{-1}$ Sodium Orthovanadate, and Protease Inhibitor Cocktail (Sigma-Aldrich, St. Louis, MO, USA). Proteins were quantified with Bradford's method [11], and the biotin switch assay with or without ascorbate $(1 \mathrm{mM})$ was performed as previously described [2,47,68]. In particular, blocking buffer (225 mmol $\mathrm{l}^{-1}$ HEPES, pH 7.7, $0.9 \mathrm{mmol} \mathrm{l}^{-1}$ EDTA, $0.09 \mathrm{mmol} \mathrm{l}^{-1}$ neocuproine, $2.5 \%$ SDS, and $20 \mathrm{mmol} \mathrm{l}^{-1}$ MMTS) and HENS buffer (250 mmol l-1 HEPES, pH 7.7, $1 \mathrm{mmol} \mathrm{l}^{-1}$ EDTA, $0.1 \mathrm{mmol}^{-1}$ neocuproine, and 1\% SDS) were used (Sigma-Aldrich, St. Louis, MO, USA) $[2,47,68]$.

To detect biotinylated proteins by Western blot, samples from the biotin switch assay were separated on $12 \%$ SDS-PAGE gels, transferred to PVDF membranes (GE Healthcare, Buckinghamshire, UK), blocked with non-fat dried milk (Santa Cruz Biotechnology, Santa Cruz, CA, U.S.A.), and incubated with streptavidin-peroxidase, diluted 1/10000 for $1 \mathrm{~h}$. To confirm equal protein loading, blots were stripped with $0.4 \mathrm{M} \mathrm{NaOH}$ and then re-blotted with an antivinculin antibody (Sigma-Aldrich, St. Louis, MO, USA). Image analyses were performed by the Kodak 1D 3.5 software $[67,68]$. Since VDAC has a cysteine residue that can be nitrosylated 
[4,57], we assessed VDAC S-Nitrosylation, using the SNO specific protein method adopted by several authors $[2,26,60,75,82,86]$, including us [68].

\section{Statistical analysis}

All values are expressed as mean \pm SE. Data were analyzed using one-way or two-way analysis of variance (ANOVA) followed by Bonferroni's post test. p Value $\leq 0.05$ was considered to be significant. 


\section{Results}

\section{Infarct size (Fig 1)}

Total infarct size, expressed as a percentage of left ventricular mass, was $63 \pm 2 \%$ in I/R Group. In I-PostC, infarct size was significantly lower, $29 \pm 2 \%$ ( $\mathrm{p}<0.01 \mathrm{vs} \mathrm{I/R}$ group). Similar results were obtained with P-PostC (Diazoxide infusion), with a significant reduction of infarct size with respect to $\mathrm{I} / \mathrm{R}$ group $(34 \pm 6 \%, \mathrm{p}<0.05$ vs $\mathrm{I} / \mathrm{R}$; NS, not significant $v s$ I-PostC). As previously reported $[18,65,84]$, the protective effects of I-PostC or P-PostC (Diazoxide infusion) were abolished by the infusion of the antioxidant MPG at the beginning of reperfusion.

\section{Western blotting}

Marker/protein levels were studied by Western-blot analysis in cytosolic and mitochondrial fractions. Representative bands and densitometric analysis of the scanned blots are presented in all the following figures. Data are normalized with respect to the mean value of the Sham group, including the raw data of Sham.

The integrity and purity of mitochondrial fraction (Fig 2)

To study mitochondrial integrity we assessed the levels of HSP60 (Fig 2A) [30]; to study the purity of mitochondrial (MF) we verified the presence of $\mathrm{Na}^{+} / \mathrm{K}^{+}$ATPase, VDAC, Lamin A/C, PLN, PDI and vinculin (Fig 2B) $[6,9,13,46,53,60,71]$, in both MF and cytosolic fraction (CF) extracted from non-ischemic (Sham), post-ischemic (I/R) and postconditioned (I-PostC and PPostC) hearts.

As expected, levels of HSP60 were lower in CF than in MF in the Sham group (see bands in Fig

$2 \mathrm{~A})$. However, the densitometry revealed that in I/R group the levels of HSP60 decreased in the MF and increased in the CF ( $\mathrm{p}<0.05$ vs all other groups for both fractions, Fig $2 \mathrm{~A})$. Since both IPostC and P-PostC maneuvers kept HSP60 levels similar to those of Sham group in both CF and 
MF, it may be inferred that these maneuvers preserved mitochondrial integrity. These results are in agreement with those obtained in our previous study [67].

As expected, VDAC, a typical protein of mitochondrial membrane, was found in the MF and was undetectable in the CF. Yet, the levels of $\mathrm{Na}^{+} / \mathrm{K}^{+}$ATPase, PLN and Lamin A/C, typical proteins of cellular membrane, sarcoplasmatic reticulum and nucleus, respectively, were undetectable in the MF and present in the remaining fraction, in all experimental groups. Together, these results suggest that our MF was substantially free of contaminants.

However, PDI and vinculin, which are considered typical of the endoplasmic reticulum and cytoskeleton, respectively, are present in both CF and MF. These findings are in agreement with the observations of several authors for endoplasmic proteins, including PDI $[48,53]$, and for cytoskeletal proteins, such as tubulin and vinculin $[13,60]$. Nevertheless, the absence of nuclear proteins in the MF is a prerequisite for the assessment of STAT3 in the SAFE pathway $[9,34,49,79]$.

P-PostC induced a redox dependent translocation to mitochondria of phosphorylated kinases of the RISK pathway (Figs 3-5)

Akt, ERK1/2 and GSK3 $\beta$ are important cardioprotective kinases of the RISK pathway in postconditioning $[33,34,79]$. Here we analyzed the role of ROS signaling in P-PostC induced mitochondrial translocation of these kinases.

Levels of Akt are reported in Fig 3. Of note, an elevated phospho/total ratio was observed in the two protected groups ( $\mathrm{p}<0.05$ vs Sham and I/R groups for both PostC protocols). Moreover, the ROS scavenger, MPG, avoided P-PostC-induced Akt phosphorylation in mitochondrial fraction. As can be seen in Fig 4, also the levels of phospho-ERK1/2 are significantly higher in the two protected groups ( $\mathrm{p}<0.05$ vs Sham and I/R Group for both PostC protocols). Again, MPG avoided P-PostC-induced ERK1/2 phosphorylation within mitochondria. 
Levels of GSK3 $\beta$ are reported in Fig 5. The phospho/total ratio of GSK3 $\beta$ resulted significantly lower in I/R group ( $<<0.05$ vs Sham), while was significantly higher in the two protected groups ( $<<0.05$ vs Sham and I/R Group for the two PostC protocols). Yet, the antioxidant, MPG, limited P-PostC-induced GSK3 $\beta$ phosphorylation in mitochondrial fraction.

As expected, phosphorylated forms of Akt, ERK1/2 and GSK3 $\beta$ were increased in the cytosolic fraction by both PostC protocols (data not shown).

SAFE pathways: only I-PostC induced a significant increase of phospho-STAT3 within mitochondria (Fig 6).

STAT3 is one of the major players of the protective SAFE pathway $[9,34,43]$ and it has been reported that in protected hearts its phosphorylation is necessary for a mitochondrial localization $[34,85]$. Therefore, to evaluate the activation of the SAFE pathway, phosphorylation of STAT3 on both Ser727and Tyr705 were studied within mitochondria (Fig 6). While I-PostC induced a significant increase of both phospho-STAT3 within mitochondria ( $\mathrm{p}<0.005 v s$ all other groups), P-PostC with Diazoxide was unable to induce a similar effect.

I-PostC and P-PostC can increase the S-Nitrosylation of mitochondrial proteins (Fig 7)

Nitric oxide has been shown to be an important mediator of cardioprotection and the addition of an NO group to a protein thiol is known as S-Nitrosylation (SNO) [62]. As can be seen in Fig 7, either I-PostC or P-PostC with Diazoxide increased SNO proteins total levels with respect to I/R group. Diazoxide given to Sham hearts induced the highest level of SNO proteins, including VDAC S-Nitrosylation. Importantly, the levels of nitrosylated VDAC are higher in postconditioned hearts than in Sham and I/R groups.

I-PostC and P-PostC could reduce the "signals of death"(Fig 8)

As expected, I/R significantly $(\mathrm{p}<0.01)$ raised all the signals of death with respect to Sham. The two cardioprotective protocols limited these increases, and maintained Sham levels for all the 
enzymes (Fig 8 panels A,C,D), with the exception of mitochondrial PKC $\delta$ levels (Fig 8, panel B), which were also reduced by the two protective protocols, but not to Sham level by P-PostC ( $\mathrm{p}<$ 0.05 P-PostC vs Sham). 


\section{Discussion}

Here we demonstrate, for the first time, that P-PostC cardioprotection with Diazoxide leads to the phosphorylation and translocation of kinases of RISK pathway to the mitochondria. This translocation is similar to what seen for preconditioning by many authors for both Diazoxide- and ischemic-preconditioning [4,32,56,75]. As far as we know, kinase translocation within mitochondria after I-PostC has been demonstrated by few authors [7,10]. Here we also demonstrate that I-PostC and P-PostC with Diazoxide induce a similar increase in S-Nitrosylation of mitochondrial proteins. Among these proteins, we detected S-Nitrosylation of VDAC, which, in fact, has a cysteine residue that can be nitrosylated and may play a critical role in the mitochondrial permeability transition pore formation $[4,35,38,57,60]$.

However, differently from I-PostC, P-PostC does not induce STAT3 mitochondrial phosphorylation. Since MPG avoids translocation of RISK elements induced by P-PostC, we suggest that the redox signaling activated by Diazoxide affects RISK- but not SAFE-pathway.

Finally, either I-PostC or P-PostC reduces the activation of signals of death caused by I/R.

S-Nitrosylation (SNO): Nitric oxide is reported to increase SNO of different mitochondrial targets [29]. Protein SNO is a redox-reversible posttranslational protein modification which may play an important cardioprotective role in PostC maneuvers. For example, NO increases SNO of complex I thereby reducing (not abolishing) ROS generation. SNO also inhibits complex V and blocks irreversible oxidation of proteins [29,62]. In addition to I-PostC, also estrogen-induced increase in contractility has been shown to involve an increase of SNO of several proteins and an upregulation of cardiac eNOS and nNOS [82].

Importantly, RISK activation in PostC results in NOS activation [33,34,79] thereby explaining increased SNO of proteins by I-PostC and indirectly by P-PostC with Diazoxide. Intriguingly, the SNO of mitochondrial proteins, including VDAC, is particularly evident when Diazoxide is given 
to non-ischemic hearts (Fig 7); thus suggesting that Diazoxide increases NO formation and favors S-Nitrosylation. Actually, it has been reported that Diazoxide increases the levels of dimethylarginine dimethylaminohydrolase (DDAH) [51]. Since DDAH metabolizes asymmetric dimethylarginine (an endogenous NOS inhibitor), Diazoxide might increase NO availability and SNO via the intervention of DDAH [23]. This deserves to be further studied.

RISK and SAFE pathways: Protective signaling molecules of RISK and SAFE are activated in response to stress to prevent cell death $[33,34,79]$. Our present results demonstrate that redoxdependent signals can start from mitochondria (Diazoxide effect) to modulate RISK, but not SAFE elements. Previous studies have suggested an essential role for ROS signaling in PostC protection $[25,69,84]$, but, to the best of our knowledge, no one has studied the role of RISK and SAFE in P-PostC with Diazoxide, a drug supposed to promote ROS signaling through actions on mitoK $_{\text {ATP }}$ channels, with the contribution of mitochondrial connexin-43 [7,10,37,71,73].

RISK: Akt and ERK1/2 are reported to phosphorylate and inhibit GSK3 $\beta$ resulting in cardioprotection via multiple targets within mitochondria [33,34].

Akt can translocate to subcellular compartments including the nucleus and mitochondria $[55,74]$. There is a correlation between Akt accumulation in mitochondria and phosphorylation/inhibition of mitochondrial GSK3 $\beta$ in these organelles [5]. Yet, GSK3 $\beta$ prefers substrates that have been previously phosphorylated by another kinase. This preference for primed substrates provides a mean to integrate multiple signaling pathways within mitochondria. Although the role of GSK3 $\beta$ seems controversial, the majority of data suggests an important role for the phosphorylation of this enzyme in a cardioprotective scenario; for a review see [80].

The mitochondrial translocation of phospho-Akt is an important signal for cardioprotection and it is observed in different models of apoptosis prevention, including neuronal and cardiac cells, where activated Akt, besides GSK3 $\beta$, may phosphorylate other mitochondrial proteins 
$[1,5,50,55]$. The importance of ERK1/2 in reperfusion in pre- and post-conditioning has been confirmed several times. For instance, Fryer et al. [28] reported rapid activation of ERK1/2 after pre-conditioning and then a second activation at 5 minutes of reperfusion, which was maintained after 30 and 60 minutes of reperfusion in the cytosolic and nuclear fractions. Yang et al. [87] and Darling et al. [22] reported that postconditioning resulted in an increase in phospho-ERK1/2 and consequent heart protection, which were abrogated by an inhibitor of ERK1/2. Although the activity of Akt in mitochondria is not well defined, the phosphorylation/activation of Akt is a pivotal event to induce cardioprotection. Accordingly, in I-PostC and in P-PostC phospho-Akt is significantly increased in the mitochondrial fraction (Fig 3). Moreover, here we report an increased mitochondria localization of phospho-ERK1/2 following I-PostC and P-PostC (Fig 4). While GSK3 $\beta$ phosphorylation/deactivation is reduced in $\mathrm{I} / \mathrm{R}$, its phosphorylation is similarly increased in the two cardioprotective protocols (Fig 5). Importantly, MPG reduces the levels of the phosphorylated forms of the three RISK elements induced by P-PostC in MF (Figs 3, 4 and 5), thus supporting an intriguing role of the ROS-signaling in the activation/translocation of RISK by P-PostC. This is in line with the ROS signaling-dependent phosphorylation of RISK elements induced by I-PostC, with or without mitochondrial translocation of kinases [7,10,17,32,62].

SAFE: in I-PostC cardioprotection enhanced STAT3-phosphorylation and improved mitochondrial function have been confirmed in several species including pigs in vivo and in vitro $[39,49]$. The action of STAT3 on cardiac mitochondria and in particular on the inhibition of mPTP opening has been recently studied by Boengler et al. [8]. We confirm the presence of both Ser- and Tyr-phosphorylated STAT3 after I-PostC within mitochondria; however the lack of increase of phospho-STAT3 after the P-PostC with Diazoxide suggests that the SAFE pathway is a parallel pathway of RISK in I-PostC only. These two pathway can be activated simultaneously (I-PostC) and, perhaps, may cross-talk [34]. However, the SAFE pathway seems not necessary. In 
fact, the direct targeting of mitochondria by Diazoxide is protective, even though does not activate SAFE pathway (i.e., Diazoxide does not reverse the tendency in phospho-STAT3 reduction induced by $I / R$ ). This is in line with the observation that mice lacking cardiac STAT3 are still protected by I-PostC [34], though the number of postconditioning cycles is a critical factor to be considered for the successful effect of I-PostC in both aged and STAT3-deficient hearts [6]. Besides STAT3, also STAT5 activation has a cardioprotective role in humans [40] and the possibility of a vicariant protective effect of these two STATs deserves to be further studied.

Signals of death: Importantly, either I-PostC or P-PostC maneuvers reduce the activation of signals of death caused by I/R. Both protocols, in fact, similarly preserve mitochondria integrity, as demonstrated by HSP60. Moreover, they also reduce cleaved caspase3, Beclin-1 and phosphorylation/translocation of $\mathrm{PKC} \delta$, which are implicated in all forms of cell death (apoptosis, autophagy and necrosis). Of note, it has been reported that increases in autophagic activity in the reperfusion phase are accompanied by upregulation of Beclin-1 in the heart [54]. Here we demonstrate that mitochondrial Beclin-1 is increased in $\mathrm{I} / \mathrm{R}$ and that this increase is prevented by either I-PostC or P-PostC. However, the signaling mechanism by which $\mathrm{I} / \mathrm{R}$ upregulates and PostC downregulates Beclin-1 expression is unknown. Notably, PKC $\delta$ may be a double-edged sword, though its phosphorylation more consistently triggers cell death [15,31,45,52,58]. Here we observe that I-PostC is more effective than P-PostC in reducing the phospho-PKC $\delta /$ total PKC $\delta$ ratio. Whether this difference is due to the lack of SAFE pathway activation in P-PostC needs to be determined.

Mitochondrial translocation of proteins and limitation of the study: In all cells an important trafficking across cytosol and mitochondria is present. However, the mechanisms for kinase trafficking is only partially known [12,59]. Heat shock proteins and potential across the mitochondrial inner membrane may play an important role in mitochondrial import of specific 
protein $[5,12]$. Future studies should investigate the mechanisms of different trafficking in IPostC and P-PostC. In a recent review of Gucek \& Murphy [29] it is reported that: "Elucidating the role of the mitochondria in cardioprotection will require a combination of examining candidate proteins as well as unbiased proteomic studies. The large-scale proteomics approach with the use of fractionation/enrichment is useful to identify unexpected protein changes. However, for low abundance signalling molecules, a targeted approach is necessary". Here we report data collected with a "targeted approach". Future proteomic and systems biology studies may analyze the mechanism of different mitochondrial protein import in cardioprotection.

In conclusion, here we show the redox-sensitive localization of many phosphorylated RISK kinases into the mitochondria following both "classic" I-PostC and P-PostC with Diazoxide. However, while I-PostC also increased phosho-STAT3 within mitochondria, P-PostC does not. This suggests that signals upstream of mitochondria are required to activate SAFE pathway leading to STAT3 phosphorylation and subsequent mitochondrial localization [39]. Yet during the two cardioprotective protocols we observe an increased S-Nitrosylation of mitochondrial proteins, such as VDAC, which is considered an important signal of cardioprotection. In fact, both protocols down-regulate molecules, which can induce the death of cardiac cells.

\section{Acknowledgement}

The authors wish to thank Prof. Donatella Gattullo for insightful suggestions and Sara Femminò for technical assistance. This work was supported by National Institutes of Cardiovascular Research (INRC-2010, to PP); Regione Piemonte (CP, PP), ex-60\% (CP, PP) and PRIN-2008 (CP).

Conflict of interest: none declared. 


\section{References}

1. Ahmad N, Wang Y, Haider KH, Wang B, Pasha Z, Uzun O, Ashraf M (2006) Cardiac protection by mitoK $_{\text {ATP }}$ channels is dependent on Akt translocation from cytosol to mitochondria during late preconditioning. Am J Physiol Heart Circ Physiol 290:H2402- H2408. doi: 10.1152/ajpheart.00737.2005.

2. Angelone T, Quintieri AM, Pasqua T, Gentile S, Tota B, Mahata SK, Cerra MC (2012) Phosphodiesterase type-2 and NO-dependent S-nitrosylation mediate the cardioinhibition of the antihypertensive catestatin. Am J Physiol Heart Circ Physiol 302:H431-H442. doi: 10.1152/ajpheart.00491.2011

3. Argaud L, Gateau-Roesch O, Augeul L, Couture-Lepetit E, Loufouat J, Gomez L, Robert D, Ovize M (2008) Increased mitochondrial calcium coexists with decreased reperfusion injury in postconditioned (but not preconditioned) hearts. Am. J. Physiol. Heart Circ Physiol 294:H386-H391. doi: 10.1152/ajpheart.01035.2007

4. Arrell DK, Elliott ST, Kane LA, Guo Y, Ko YH, Pedersen PL, Robinson J, Murata M, Murphy AM, Marbán E, Van Eyk JE (2006) Proteomic analysis of pharmacological preconditioning: novel protein targets converge to mitochondrial metabolism pathways. Circ Res 99:706-714. doi: 10.1161/01.RES.0000243995.74395.f8

5. Bijur GN, Jope RS (2003) Rapid accumulation of Akt in mitochondria following phosphatidylinositol 3-kinase activation. J Neurochem 87:1427-1435. doi: 10.1046/j.1471-4159.2003.02113.x

6. Boengler K, Buechert A, Heinen Y, Roeskes C, Hilfiker-Kleiner D, Heusch G, Schulz R (2008) Cardioprotection by ischemic postconditioning is lost in aged and STAT3deficient mice. Circ Res 102:131-135. doi: 10.1161/CIRCRESAHA.107.164699 
7. Boengler K, Heusch G, Schulz R (2011) Mitochondria in postconditioning. Antioxid Redox Signal 14:863-880. doi: 10.1089/ars.2010.3309

8. Boengler K, Heusch G, Schulz R (2011) Nuclear-encoded mitochondrial proteins and their role in cardioprotection. Biochim Biophys Acta 1813:1286-194. doi: 10.1016/j.bbamcr.2011.01.009

9. Boengler K, Hilfiker-Kleiner D, Heusch G, Schulz R (2010) Inhibition of permeability transition pore opening by mitochondrial STAT3 and its role in myocardial ischemia/reperfusion. Basic Res Cardiol 105:771-785. doi: 10.1007/s00395-010-01241

10. Boengler K, Konietzka I, Buechert A, Heinen Y, Garcia-Dorado D, Heusch G, Schulz $\mathrm{R}$ (2007) Loss of ischemic preconditioning's cardioprotection in aged mouse hearts is associated with reduced gap junctional and mitochondrial levels of connexin 43. Am J Physiol Heart Circ Physiol 292:H1764-H1769. doi: 10.1152/ajpheart.01071.2006

11. Bradford MM (1976) A rapid and sensitive method for the quantitation of microgram quantities of protein utilizing the principle of protein-dye binding. Anal Biochem $7: 248-254$.

12. Budas GR, Churchill EN, Disatnik MH, Sun L, Mochly-Rosen D (2010) Mitochondrial import of PKCepsilon is mediated by HSP90: a role in cardioprotection from ischaemia and reperfusion injury. Cardiovasc Res 88:83-92. doi: $10.1093 / \mathrm{cvr} / \mathrm{cvq} 180$

13. Carré M, André N, Carles G, Borghi H, Brichese L, Briand C, Braguer D (2002) Tubulin is an inherent component of mitochondrial membranes that interacts with the voltage-dependent anion channel. J Biol Chem 277:33664-33669. doi: 10.1074/jbc.M203834200 
14. Carroll R, Gant VA, Yellon DM (2001) Mitochondrial $\mathrm{K}_{\mathrm{ATP}}$ channels protects a human atrial-derived cell line by a mechanism involving free radical generation. Cardiovasc Res 51:691-700. doi: 10.1016/S0008-6363(01)00330-3

15. Churchill EN, Mochly-Rosen D (2007) The roles of PKCdelta and epsilon isoenzymes in the regulation of myocardial ischaemia/reperfusion injury. Biochem Soc Trans 35:1040-1042. doi: 10.1042/BST0351040

16. Churchill EN, Szweda LI (2005) Translocation of deltaPKC to mitochondria during cardiac reperfusion enhances superoxide anion production and induces loss in mitochondrial function. Arch Biochem Biophys 439:194-199. doi: 10.1016/j.abb.2005.05.007

17. Cohen MV, Downey JM (2011) Ischemic postconditioning: from receptor to endeffector. Antioxid. Redox Signal 14:821-831. doi: 10.1089/ars.2010.3318.

18. Cohen MV, Yang XM, Downey JM (2007) The pH hypothesis of postconditioning: staccato reperfusion reintroduces oxygen and perpetuates myocardial acidosis. Circulation 115:1895-1903. doi: 10.1161/CIRCULATIONAHA.106.675710

19. Costa AD, Garlid KD, West IC, Lincoln TM, Downey JM, Cohen MV, Critz SD (2005) Protein kinase $G$ transmits the cardioprotective signal from cytosol to mitochondria. Circ Res 97:329-336. doi: 10.1161/01.RES.0000178451.08719.5b

20. Crow MT, Mani K, Nam YJ, Kitsis RN (2004) The mitochondrial death pathway and cardiac myocyte apoptosis. Circ Res 95:957-970. doi: 10.1161/01.RES.0000148632.35500.d9

21. Danial NN, Korsmeyer SJ (2004) Cell death: critical control points. Cell 116:205-219. doi: 10.1016/S0092-8674(04)00046-7 
22. Darling CE, Jiang R, Maynard M, Whittaker P, Vinten-Johansen J, Przyklenk K (2005) Postconditioning via stuttering reperfusion limits myocardial infarct size in rabbit hearts: role of ERK1/2. Am J Physiol Heart Circ Physiol 289:H1618- H1626. doi: 10.1152/ajpheart. 00055.2005

23. Dayoub H, Achan V, Adimoolam S, Jacobi J, Stuehlinger MC, Wang BY, Tsao PS, Kimoto M, Vallance P, Patterson AJ, Cooke JP (2003) Dimethylarginine dimethylaminohydrolase regulates nitric oxide synthesis: genetic and physiological evidence. Circulation 108:3042-3047. doi: 10.1161/01.CIR.0000101924.04515.2E

24. Di Lisa F, Canton M, Carpi A, Kaludercic N, Menabò R, Menazza S, Semenzato M (2011) Mitochondrial injury and protection in ischemic pre- and postconditioning. Antioxid Redox Signal 14:881-891. doi: 10.1089/ars.2010.3375.

25. Downey JM, Cohen MV (2006) A really radical observation--a comment on Penna et al. in Basic Res Cardiol (2006) 101:180-189. Basic Res Cardiol 101:190-1. doi: $10.1007 / \mathrm{s} 00395-006-0586-3$

26. Filice E, Angelone T, De Francesco EM, Pellegrino D, Maggiolini M, Cerra MC (2011) Crucial role of phospholamban phosphorylation and S-nitrosylation in the negative lusitropism induced by $17 \beta$-estradiol in the male rat heart. Cell Physiol Biochem 28:41-52. doi: 10.1159/000331712.

27. Forbes RA, Steenbergen C, Murphy E (2001) Diazoxide-induced cardioprotection requires signaling through a redox-sensitive mechanism. Circ Res 88:802-809. doi: $10.1161 / \mathrm{hh} 0801.089342$

28. Fryer RM, Pratt PF, Hsu AK, Gross GJ (2001) Differential activation of extracellular signal regulated kinase isoforms in preconditioning and opioid-induced cardioprotection. J Pharmacol Exp Ther 296:642-649. 
29. Gucek M, Murphy E (2010) What can we learn about cardioprotection from the cardiac mitochondrial proteome? Cardiovasc Res 88:211-218. doi: $10.1093 / \mathrm{cvr} / \mathrm{cvq} 277$

30. Hansson CA, Frykman S, Farmery MR, Tjernberg LO, Nilsberth C, Pursglove SE, Ito A, Winblad B, Cowburn RF, Thyberg J, Ankarcrona M (2004) Nicastrin, presenilin, APH-1, and PEN-2 form active gamma-secretase complexes in mitochondria. J Biol Chem 279:51654-51660. doi: 10.1074/jbc.M404500200

31. Harada N, Miura T, Dairaku Y, Kametani R, Shibuya M, Wang R, Kawamura S, Matsuzaki M (2004) NO donor-activated PKC-delta plays a pivotal role in ischemic myocardial protection through accelerated opening of mitochondrial K-ATP channels. J Cardiovasc Pharmacol 44:35-41. doi: 10.1097/00005344-200407000-00005

32. Hausenloy D, Wynne A, Duchen M, Yellon D (2004) Transient mitochondrial permeability transition pore opening mediates preconditioning induced protection. Circulation 109:1714-1717. doi: 10.1161/01.CIR.0000126294.81407.7D

33. Hausenloy DJ, Baxter G, Bell R, Bøtker HE, Davidson SM, Downey J, Heusch G, Kitakaze M, Lecour S, Mentzer R, Mocanu MM, Ovize M, Schulz R, Shannon R, Walker M, Walkinshaw G, Yellon DM (2010) Translating novel strategies for cardioprotection: the Hatter Workshop Recommendations. Basic Res Cardiol 105:677686. doi: 10.1007/s00395-010-0121-4

34. Hausenloy DJ, Lecour S, Yellon DM (2011) Reperfusion injury salvage kinase and survivor activating factor enhancement prosurvival signaling pathways in ischemic postconditioning: two sides of the same coin. Antioxid Redox Signal 14:893-907. doi:10.1089/ars.2010.3360. 
35. Hausenloy DJ, Ong SB, Yellon DM (2009) The mitochondrial permeability transition pore as a target for preconditioning and postconditioning. Basic Res Cardiol 104:189202. doi: 10.1007/s00395-009-0010-x.

36. Hausenloy DJ, Yellon DM (2006) Survival kinases in ischemic preconditioning and postconditioning. Cardiovasc Res 70:240-253. doi: 10.1016/j.cardiores.2006.01.017

37. Heinzel FR, Luo Y, Li X, Boengler K, Buechert A, García-Dorado D, Di Lisa F, Schulz R, Heusch G (2005) Impairment of diazoxide-induced formation of reactive oxygen species and loss of cardioprotection in connexin 43 deficient mice. Circ Res 97:583-586. doi: 10.1161/01.RES.0000181171.65293.65

38. Heusch G, Boengler K, Schulz R (2010) Inhibition of mitochondrial permeability transition pore opening: the Holy Grail of cardioprotection. Basic Res Cardiol 105:151-154. doi: 10.1007/s00395-009-0080-9

39. Heusch G, Musiolik J, Gedik N, Skyschally A (2011) Mitochondrial STAT3 activation and cardioprotection by ischemic postconditioning in pigs with regional myocardial ischemia/reperfusion. Circ Res 109:1302-1308. doi: 10.1161/CIRCRESAHA.111.255604.

40. Heusch G, Musiolik J, Kottenberg E, Peters J, Jakob H, Thielmann M (2012) STAT5 activation and cardioprotection by remote ischemic preconditioning in humans: short communication. Circ Res110:111-115. doi: 10.1161/CIRCRESAHA.111.259556.

41. Heusch G (2004) Postconditioning: old wine in a new bottle? J Am Coll Cardiol 44:1111-1112. doi: 10.1016/j.jacc.2004.06.013

42. Heusch G (2012) Reduction of infarct size by ischaemic post-conditioning in humans: fact or fiction? Eur Heart J 33:13-15. doi: 10.1007/s00059-008-3101-9 
43. Hilfiker-Kleiner D, Hilfiker A, Fuchs M, Kaminski K, Schaefer A, Schieffer B, Hillmer A, Schmiedl A, Ding Z, Podewski E, Podewski E, Poli V, Schneider MD, Schulz R, Park JK, Wollert KC, Drexler H (2004) Signal transducer and activator of transcription 3 is required for myocardial capillary growth, control of interstitial matrix deposition, and heart protection from ischemic injury. Circ Res 95:187-195. doi: 10.1161/01.RES.0000134921.50377.61

44. Hofstaetter B, Taimor G, Inserte J, Garcia-Dorado D, Piper HM. Inhibition of apoptotic responses after ischemic stress in isolated hearts and cardiomyocytes. Basic Res Cardiol 97: 479-488, 2002. doi: 10.1007/s003950200053

45. Ikeno F, Inagaki K, Rezaee M, Mochly-Rosen D (2007) Impaired perfusion after myocardial infarction is due to reperfusion-induced deltaPKC-mediated myocardial damage. Cardiovasc Res 73:699-709. doi: 10.1016/j.cardiores.2006.12.011

46. Ivanes F, Rioufol G, Piot C, Ovize M (2011) Postconditioning in acute myocardial infarction patients. Antioxid Redox Signal 14:811-820. doi: 10.1089/ars.2010.3354.

47. Jaffrey SR, Snyder SH (2001) The biotin switch method for the detection of Snitrosylated proteins. Sci STKE 86:PL1. doi: 10.1126/stke.2001.86.pl1

48. Kimura T, Horibe T, Sakamoto C, Shitara Y, Fujiwara F, Komiya T, Yamamoto A, Hayano T, Takahashi N, Kikuchi M (2008) Evidence for mitochondrial localization of P5, a member of the protein disulphide isomerase family. J Biochem 144:187-196. doi: $10.1093 / \mathrm{jb} / \mathrm{mvn} 057$.

49. Lacerda L, Somers S, Opie LH, Lecour S (2009) Ischaemic postconditioning protects against reperfusion injury via the SAFE pathway. Cardiovasc Res 84:201-208. doi: $10.1093 / \mathrm{cvr} / \mathrm{cvp} 274$. 
50. Lai HC, Liu TJ, Ting CT, Sharma PM, Wang PH (2003) Insulin-like growth factor-1 prevents loss of electrochemical gradient in cardiac muscle mitochondria via activation of PI3kinase/Akt pathway. Mol Cell Endocrinol 205:99-106. doi: $10.1016 /$ S0303-7207(03)00200-4

51. Li H, Xiao YB, Gao YQ, Yang TD (2006) Comparative proteomics analysis of differentially expressed phosphoproteins in adult rat ventricular myocytes subjected to diazoxide preconditioning. Drug Metabol Drug Interact 21:245-258.

52. Liu H, McPherson BC, Yao Z (2001) Preconditioning attenuates apoptosis and necrosis: role of protein kinase $\mathrm{C}$ epsilon and -delta isoforms. Am J Physiol Heart Circ Physiol 281:H404-H410.

53. Malorni W, Farrace MG, Matarrese P, Tinari A, Ciarlo L, Mousavi-Shafaei P, D'Eletto M, Di Giacomo G, Melino G, Palmieri L, Rodolfo C, Piacentini M (2009) The adenine nucleotide translocator 1 acts as a type 2 transglutaminase substrate: implications for mitochondrial-dependent apoptosis. Cell Death Differ 16:1480-1492. doi: 10.1038/cdd.2009.100.

54. Matsui Y, Takagi H, Qu X, Abdellatif M, Sakoda H, Asano T, Levine B, Sadoshima J (2007) Distinct roles of autophagy in the heart during ischemia and reperfusion: roles of AMP-activated protein kinase and Beclin 1 in mediating autophagy. Circ Res 100:914-922. doi: 10.1161/01.RES.0000261924.76669.36

55. Miyamoto S, Murphy AN, Brown JH (2009) Akt mediated mitochondrial protection in the heart: metabolic and survival pathways to the rescue. J Bioenerg Biomembr 41:169-180. doi: 10.1007/s10863-009-9205-y

56. Murphy E, Steenbergen C (2007) Preconditioning: the mitochondrial connection. Annu Rev Physiol 69:51-67. doi: 10.1146/annurev.physiol.69.031905.163645 
57. Murray CI, Kane LA, Uhrigshardt H, Wang SB, Van Eyk JE (2011) Site-mapping of in vitro S-nitrosation in cardiac mitochondria: implications for cardioprotection. Mol Cell Proteomics 10:M110.004721. doi: 10.1074/mcp.M110.004721

58. Murriel CL, Mochly-Rosen D (2003) Opposing roles of delta and epsilon PKC in cardiac ischemia and reperfusion: targeting the apoptotic machinery. Arch Biochem Biophys 420: 246-254. doi: 10.1016/j.abb.2003.08.038

59. Neupert W, Brunner M (2002) The protein import motor of mitochondria. Nat Rev Mol Cell Biol 3:555-565. doi: 10.1038/nrm878

60. Nguyen T, Wong R, Wang G, Gucek M, Steenbergen C, Murphy E (2012) Acute inhibition of GSK causes mitochondrial remodeling. Am J Physiol Heart Circ Physiol 302:H2439-H2445. doi: 10.1152/ajpheart.00033.2012.

61. Pagliaro P, Mancardi D, Rastaldo R, Penna C, Gattullo D, Miranda KM, Feelisch M, Wink DA, Kass DA, Paolocci N. Nitroxyl affords thiol-sensitive myocardial protective effects akin to early preconditioning. Free Radic Biol Med 34:33-43, 2003. doi: $10.1016 / \mathrm{S} 0891-5849(02) 01179-6$

62. Pagliaro P, Moro F, Tullio F, Perrelli MG, Penna C (2011) Cardioprotective pathways during reperfusion: focus on redox signaling and other modalities of cell signaling. Antioxid Redox Signal 14:833-850. doi: 10.1089/ars.2010.3245

63. Penna C, Cappello S, Mancardi D, Raimondo S, Rastaldo R, Gattullo D, Losano G, Pagliaro P (2006) Post-conditioning reduces infarct size in the isolated rat heart: role of coronary flow and pressure and the nitric oxide/cGMP pathway. Basic Res Cardiol 101:168-179. doi: 10.1007/s00395-005-0543-6 
64. Penna C, Mancardi D, Raimondo S, Geuna S, Pagliaro P (2008) The paradigm of postconditioning to protect the heart. J Cell Mol Med 12:435-458. doi: 10.1111/j.1582-4934.2007.00210.x

65. Penna C, Mancardi D, Rastaldo R, Losano G, Pagliaro P (2007) Intermittent activation of bradykinin $\mathrm{B}_{2}$ receptors and mitochondrial $\mathrm{K}_{\mathrm{ATP}}$ channels trigger cardiac postconditioning through redox signaling. Cardiovasc Res 75:168-177. doi:10.1016/j.cardiores.2007.03.001

66. Penna C, Perrelli MG, Pagliaro P (2013) Mitochondrial Pathways, Permeability Transition Pore, and Redox Signaling in Cardioprotection: Therapeutic Implications. Antioxid Redox Signal 18:556-99. doi: 10.1089/ars.2011.4459

67. Penna C, Perrelli MG, Raimondo S, Tullio F, Merlino A, Moro F, Geuna S, Mancardi, D, Pagliaro P (2009) Postconditioning induces an anti-apoptotic effect and preserves mitochondrial integrity in isolated rat hearts. Biochim Biophys Acta 1787:794-801. doi: 10.1016/j.bbabio.2009.03.013

68. Penna C, Perrelli MG, Tullio F, Moro F, Parisella ML, Merlino A, Pagliaro P (2011) Post-ischemic early acidosis in cardiac postconditioning modifies the activity of antioxidant enzymes, reduces nitration, and favors protein S-nitrosylation. Pflugers Arch 462:219-233. doi: 10.4330/wjc.v3.i6.186

69. Penna C, Rastaldo R, Mancardi D, Raimondo S, Cappello S, Gattullo D, Losano G, Pagliaro P (2006) Post-conditioning induced cardioprotection requires signaling through a redox-sensitive mechanism, mitochondrial ATP-sensitive $\mathrm{K}^{+}$channel and protein kinase C activation. Basic Res Cardiol 101:180-9. doi: 10.1007/s00395-006$0584-5$ 
70. Perrelli MG, Pagliaro P, Penna C (2011) Ischemia/reperfusion injury and cardioprotective mechanisms: Role of mitochondria and reactive oxygen species. World J Cardiol 3:186-200. doi: 10.4330/wjc.v3.i6.186

71. Rodriguez-Sinovas A, Boengler K, Cabestrero A, Gres P, Morente M, Ruiz-Meana M, Konietzka I, Miró E, Totzeck A, Heusch G, Schulz R, Garcia-Dorado D (2006) Translocation of connexin 43 to the inner mitochondrial membrane of cardiomyocytes through the heat shock protein 90-dependent TOM pathway and its importance for cardioprotection. Circ Res 99:93-101. doi: 10.1161/01.RES.0000230315.56904.de

72. Sanada S, Komuro I, Kitakaze M (2011) Pathophysiology of myocardial reperfusion injury: preconditioning, postconditioning, and translational aspects of protective measures. Am J Physiol Heart Circ Physiol 301:H1723- H1741. doi: 10.1152/ajpheart.00553.2011

73. Sánchez JA, Rodríguez-Sinovas A, Barba I, Miró-Casas E, Fernández-Sanz C, RuizMeana M, Alburquerque-Béjar JJ, García-Dorado D (2013) Activation of RISK and SAFE pathways is not involved in the effects of $\mathrm{Cx} 43$ deficiency on tolerance to ischemia-reperfusion injury and preconditioning protection. Basic Res Cardiol 108:351. doi: 10.1007/s00395-013-0351-3

74. Sasaki K, Sato M, Umezawa, Y (2003) Fluorescent indicators for Akt/protein kinase B and dynamics of Akt activity visualized in living cells. J Biol Chem 278:30945-30951. doi: 10.1074/jbc.M212167200

75. Sivaraman V, Mudalagiri NR, Di Salvo C, Kolvekar S, Hayward M, Yap J, Keogh B, Hausenloy DJ, Yellon DM (2007) Postconditioning protects human atrial muscle through the activation of the RISK pathway. Basic Res Cardiol 102: 453-459. doi: 10.1007/s00395-007-0664-1 
76. Skyschally A, Schulz R, Heusch G (2008) Pathophysiology of myocardial infarction: protection by ischemic pre- and postconditioning. Herz 33:88-100. doi: 10.1007/s00059-008-3101-9

77. Skyschally A, van Caster P, Boengler K, Gres P, Musiolik J, Schilawa D, SchulzR, Heusch G (2009) Ischemic postconditioning in pigs: no causal role for RISK activation. Circ Res 104:15-18. doi: 10.1161/CIRCRESAHA.108.186429

78. Skyschally A, van Caster P, Iliodromitis EK, Schulz R, Kremastinos DT, Heusch G (2009) Ischemic postconditioning: experimental models and protocol algorithms. Basic Res Cardiol 104:469-83. doi: 10.1007/s00395-009-0040-4

79. Somers SJ, Frias M, Lacerda L, Opie LH, Lecour S (2012) Interplay between SAFE and RISK pathways in sphingosine-1-phosphate-induced cardioprotection. Cardiovasc Drugs Ther 26:227-237. doi: 10.1007/s10557-012-6376-2

80. Steenbergen C, Das S, Su J, Wong R, Murphy E (2009) Cardioprotection and altered mitochondrial adenine nucleotide transport. Basic Res Cardiol 104:149-156. doi: 10.1007/s00395-009-0002-x.

81. Sun HY, Wang NP, Halkos M, Kerendi F, Kin H, Guyton RA, Vinten-Johansen J, Zhao ZQ (2006) Postconditioning attenuates cardiomyocyte apoptosis via inhibition of JNK and p38 mitogen-activated protein kinase signaling pathways. Apoptosis 11:1583-1593. doi: 10.1007/s10495-006-9037-8

82. Sun J, Murphy E (2010) Protein S-Nitrosylation and Cardioprotection. Circ Res 106: 285-296. doi: 10.1161/CIRCRESAHA.109.209452

83. Sun J, Picht E, Ginsburg KS, Bers DM, Steenbergen C, Murphy E (2006) Hypercontractile female hearts exhibit increased S-nitrosylation of the L-type $\mathrm{Ca}^{2+}$ 
Channel $\alpha 1$ subunit and reduced Ischemia/Reperfusion Injury. Circ Res 98: 403-411. doi: 10.1161/01.RES.0000202707.79018.0a

84. Tsutsumi YM, Yokoyama T, Horikawa Y, Roth DM, Patel HH (2007) Reactive oxygen species trigger ischemic and pharmacological postconditioning: in vivo and in vitro characterization. Life Sci 81:1223-1227. doi: 10.1016/j.lfs.2007.08.031

85. Wegrzyn J, Potla R, Chwae YJ, Sepuri NB, Zhang Q, Koeck T, Derecka M, Szczepanek K, Szelag M, Gornicka A, Moh A, Moghaddas S, Chen Q, Bobbili S, Cichy J, Dulak J, Baker DP, Wolfman A, Stuehr D, Hassan MO, Fu XY, Avadhani N, Drake JI, Fawcett P, Lesnefsky EJ, Larner AC (2009) Function of mitochondrial Stat3 in cellular respiration. Science 323:793-797. doi: 10.1126/science.1164551

86. Yang BK, Vivas EX, Reiter CD, Gladwin MT (2003) Methodologies for the sensitive and specific measurement of S-nitrosothiols, iron-nitrosyls, and nitrite in biological samples. Free Radic Res 37:1-10. doi: 10.1080/1071576021000033112

87. Yang XM, Philipp S, Downey JM, Cohen MV (2005) Postconditioning's protection is not dependent on circulating blood factors or cells but involves adenosine receptors and requires PI3-kinase and guanylyl cyclase activation. Basic Res Cardiol 100:57-63. doi: 10.1007/s00395-004-0498-4

88. Yellon DM, Hausenloy DJ (2007) Myocardial reperfusion injury. N Engl J Med 357:1121-35. doi: 10.1056/NEJMra071667

89. Zhao ZQ, Corvera JS, Halkos ME, Kerendi F, Wang NP, Guyton RA, VintenJohansen J (2003) Inhibition of myocardial injury by ischemic postconditioning during reperfusion: comparison with ischemic preconditioning. Am J Physiol Heart Circ Physiol 285:H579-H588. doi: 10.1152/ajpheart.01064.2002 


\section{Figure Legends}

\section{Figure 1. Infarct size (IS).}

The amount of necrotic tissue is expressed as percent of the left ventricle (LV), which is considered the risk area. I/R: ischemia/reperfusion; I-PostC: ischemic postconditioning; PPostC: pharmacological postconditioning with Diazoxide; I-PostC+MPG: the antioxidant MPG was given during I-PostC maneuvers; P-PostC+MPG: MPG was co-infused with Diazoxide. ${ }^{* *} \mathrm{p}<0.01$ and $* \mathrm{p}<0.05$ Vs. I/R. NS: not significant.

\section{Figure 2. Integrity and Purity of Isolated Mitochondria.}

A) Levels of HSP60 are used as indices of the integrity of mitochondria in non-ischemic (Sham), post-ischemic (I/R) and postconditioned (I-PostC and P-PostC) groups. Mean \pm SE of HSP60 levels in mitochondrial and cytosolic as well as HSP60 representative blots are reported. Data are expressed in arbitrary units (a.u.) and normalized for loading controls. *p $<0.05$ vs Sham.

B) The presence of $\mathrm{Na}+\mathrm{K}+$ ATPase, voltage-dependent anion-selective channel (VDAC), protein disulfide isomerase (PDI), Lamin A/C, Phospholamban (PLN) and Vinculin is used as index of the purity of mitochondria in Sham, I/R, I-PostC and P-PostC groups. Representative blots of bands from mitochondrial and cytosolic fractions are reported.

Figure 3. Mitochondrial Akt. 
Levels of total and phosphorylated Akt (phospho-Akt) have been analyzed in Sham, I/R, IPostC, P-PostC, Sham+MPG and P-PostC+MPG groups. Mean \pm SE of the relative phosphoAkt/total Akt ratio in mitochondrial fraction and their representative blots are reported. Data are normalized for loading control (HADHA) and then with respect to mean value of Sham group. ${ }^{*} \mathrm{p}<0.05$ vs Sham; \# $\mathrm{p}<0.05$ vs I/R. NS: not significant.

\section{Figure 4 Mitochondrial ERK1/2.}

Levels of total and phosphorylated ERK1/2 (phospho-ERK1/2) have been analyzed in Sham,

I/R, I-PostC, P-PostC groups, Sham+MPG and P-PostC+MPG groups. Mean \pm SE of the relative phospho-ERK1/2/total ERK1/2 ratio in mitochondrial fraction and their representative blots are reported. Data are normalized for loading control (HADHA) and then with respect to mean value of Sham group. ${ }^{*} \mathrm{p}<0.05$ vs Sham; \# $\mathrm{p}<0.05$ vs I/R. NS: not significant.

Figure 5. Mitochondrial GSK3ß.

Levels of total and phosphorylated GSK3 $\beta$ (phospho- GSK3 $\beta$ ) have been analyzed in Sham, I/R, I-PostC, P-PostC, Sham + MPG and P-PostC + MPG groups. Mean \pm SE of the relative phospho-GSK3 $3 /$ total GSK3 $\beta$ ratio in mitochondrial fraction and their representative blots are reported. Data are normalized for loading control (HADHA) and then with respect to mean value of Sham group. ${ }^{*} \mathrm{p}<0.05$ vs Sham; \# $\mathrm{p}<0.05$ vs I/R. NS: not significant.

Figure 6. Mitochondrial p-Ser-STAT3. 
Levels of total and phosphorylated in Ser-STAT3 (p-Ser-STAT3) and in Tyr-STAT3 (p-TyrSTAT3) have been analyzed in I/R, I-PostC and P-PostC groups. Mean \pm SE of the relative phospho-STAT3/total STAT3 ratio (for both sites of phosphorylation) in mitochondrial fraction and their representative blots are reported. Data are normalized for loading control (HADHA) and then with respect to mean value of Sham group. ${ }^{* *} \mathrm{p}<0.01$ vs Sham; \#\# $\mathrm{p}<$ $0.05 v s \mathrm{I} / \mathrm{R}$.

\section{Figure 7. S-Nitrosylation (SNO) of Mitochondrial Proteins.}

Levels of total SNO proteins have been analyzed by biotin switch assay in the mitochondrial fraction of the Sham, Sham+DZO, I/R, I-PostC and P-PostC groups. To verify the specificity of the biotin switch assay, ascorbate has been omitted in Sham samples (-Asc). The analysis of total bands shows an increase in S-Nitrosylation in I-PostC and P-PostC as well as in Sham + DZO. Mean \pm SE of the levels of SNO proteins in mitochondrial fraction and their representative blots are reported. Data are reported as normalized arbitrary units (a.u.). Specific protein analysis shows an increased SNO of VDAC in I-PostC, P-PostC and in Sham+DZO. *p<0.05 vs Sham; \# $\mathrm{p}<0.05$ vs I/R. **p<0.05 vs Sham; \#\# $\mathrm{p}<0.05$ vs I/R. NS: not significant.

Figure 8. Death Signals.

A and B) Cytosolic and Mitochondrial PKC $\delta$. Levels of total and phosphorylated PKC $\delta$ (p$\mathrm{PKC} \delta$ ) have been analyzed in non-ischemic (Sham), post-ischemic (I/R) and postconditioned 
(I-PostC and P-PostC) groups in both in cytosolic and mitochondrial fractions. Presented bands were not juxtaposed in the original film. Data are normalized for loading control (vinculin or HADHA) and then with respect to mean value of Sham group. Mean \pm SE of the relative phospho-PKC $\delta /$ total $\mathrm{PKC} \delta$ ratio in mitochondrial and cytosolic fraction and their representative blots are reported. ${ }^{*} \mathrm{p}<0.01$ vs all other groups; \# $\mathrm{p}<0.05$ vs I/R.

C) Cytosolic cleaved-caspase-3. Levels of cleaved-caspase-3 have been analyzed in the cytosolic fraction of the four experimental groups (Sham, I/R, I-PostC and P-PostC groups). Data are normalized for loading control (vinculin) and then with respect to mean value of Sham group. Mean \pm SE in cytosolic fraction and their representative blots are reported. $* * \mathrm{p}<0.01 v s$ all other groups

D) Mitochondrial Beclin-1. Levels of Beclin-1 have been analyzed in the mitochondrial fraction of the four experimental groups (Sham, I/R, I-PostC and P-PostC groups). Data are normalized for loading control (HADHA) and then with respect to mean value of Sham group. Mean \pm SE in cytosolic fraction and their representative blots are reported. ${ }^{* *} \mathrm{p}<0.01$ vs all other groups. 


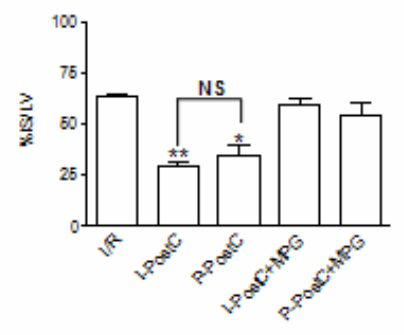

Fig.1

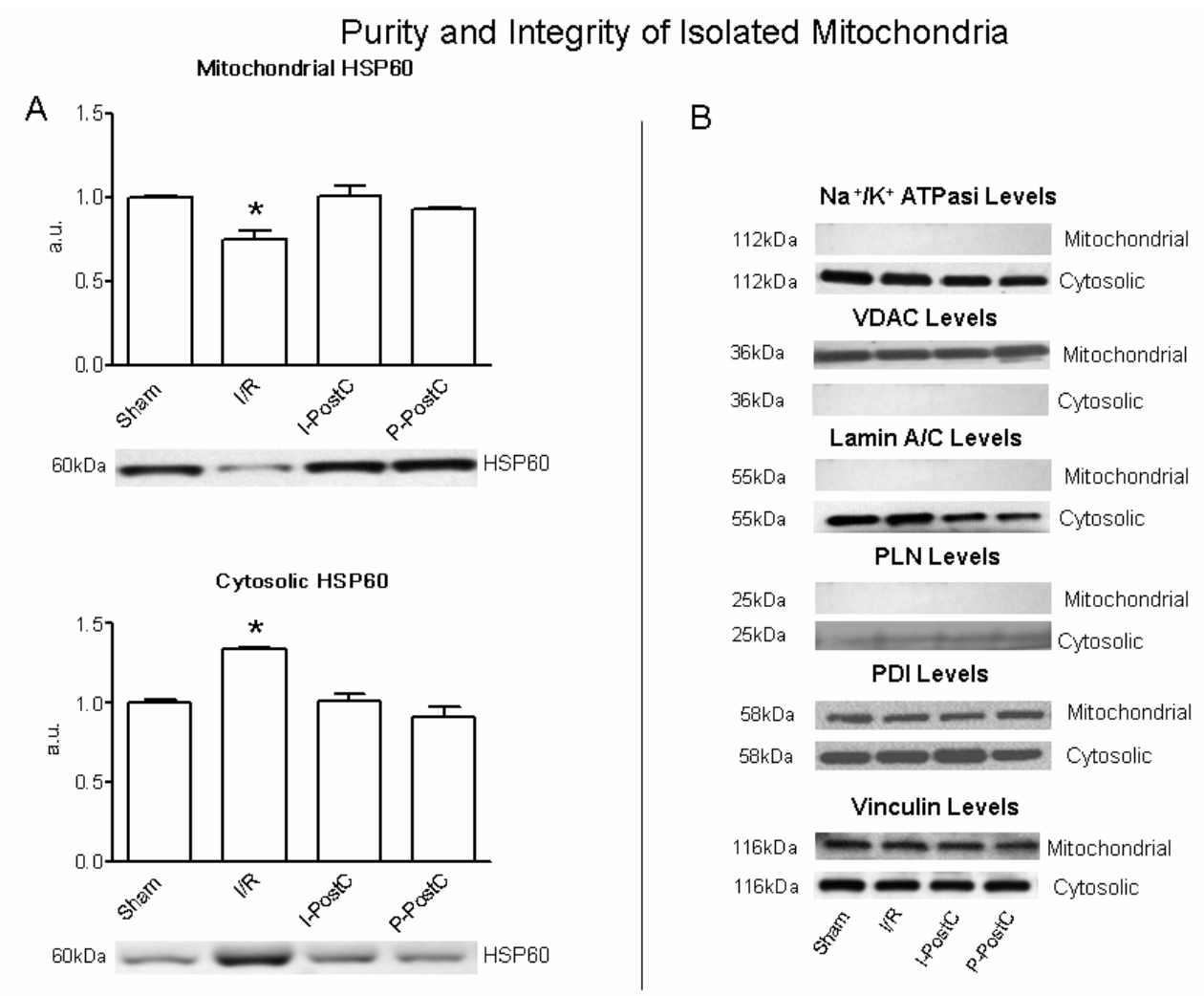

Fig.2 


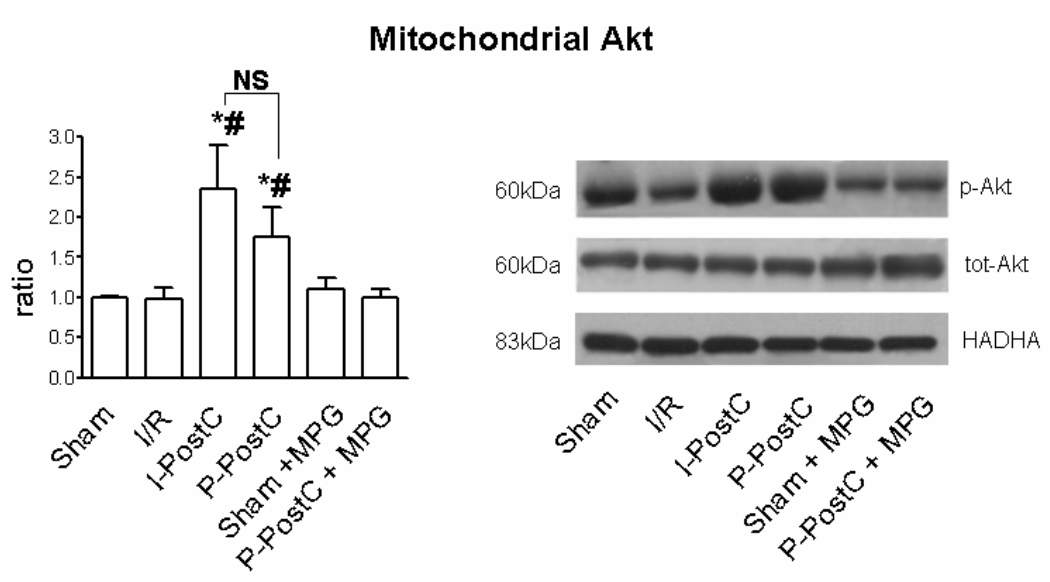

Fig. 3

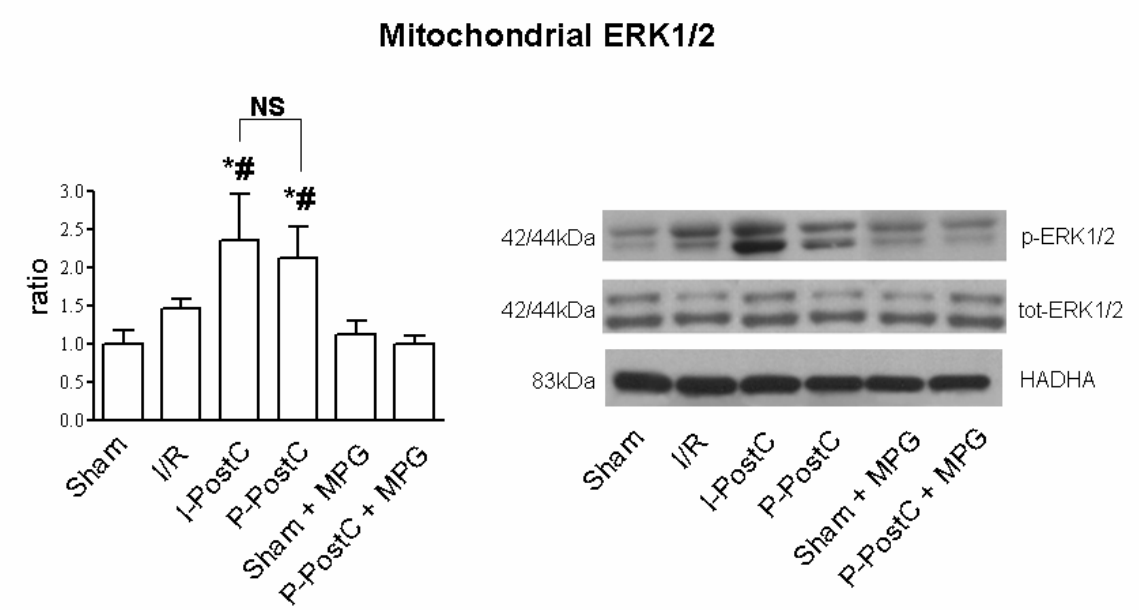

Fig.4 


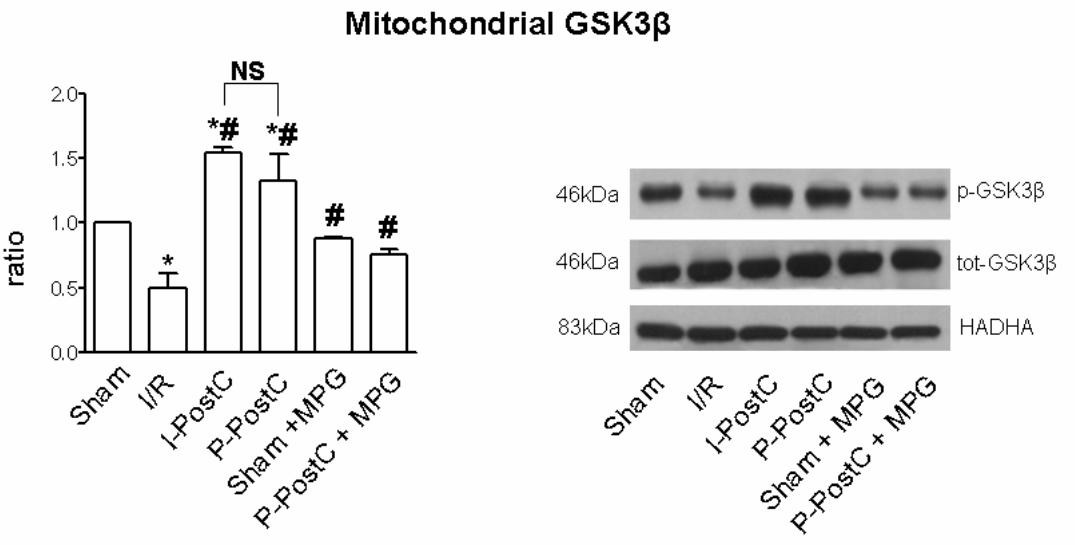

Fig.5

Mitochondrial p-Ser-STAT3

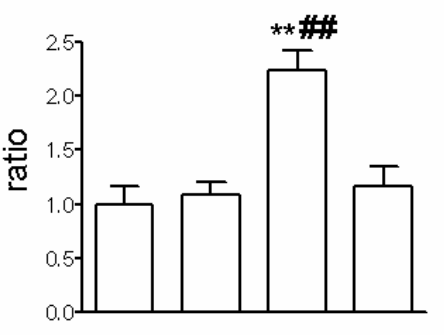

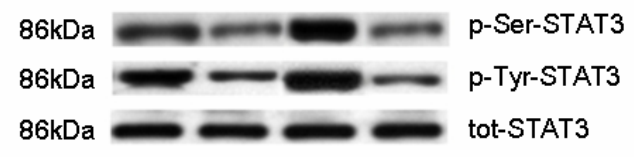

Mitochondrial p-Tyr-STAT3

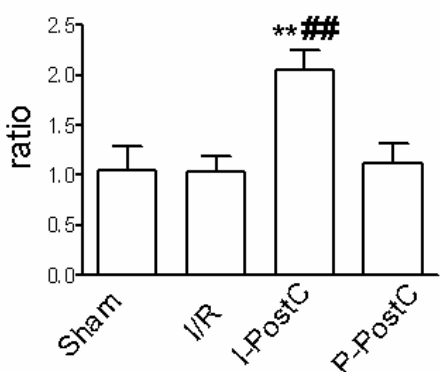

$83 \mathrm{kDa}=$ HADHA

$5^{\text {है }} \leqslant 8^{8^{\circ}}$

Fig.6 
S-Nitrosylation of Mitochondrial Proteins
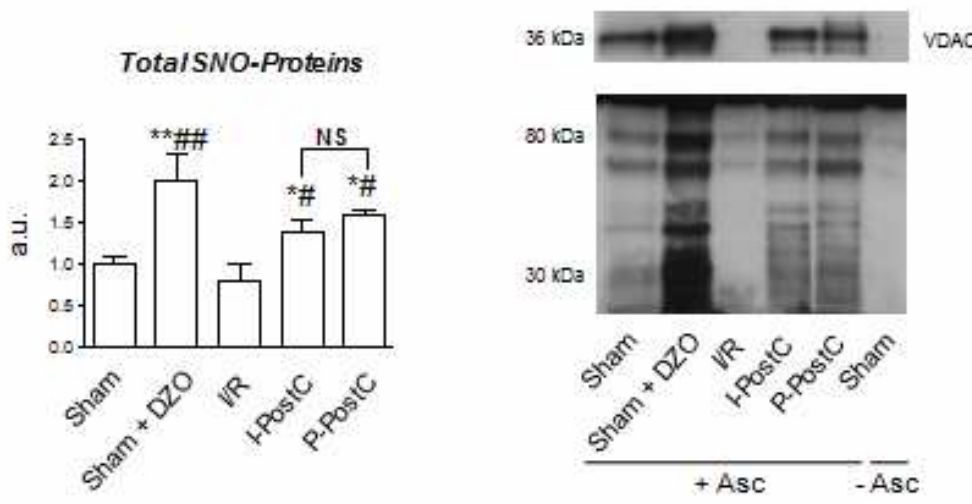

Fig.7

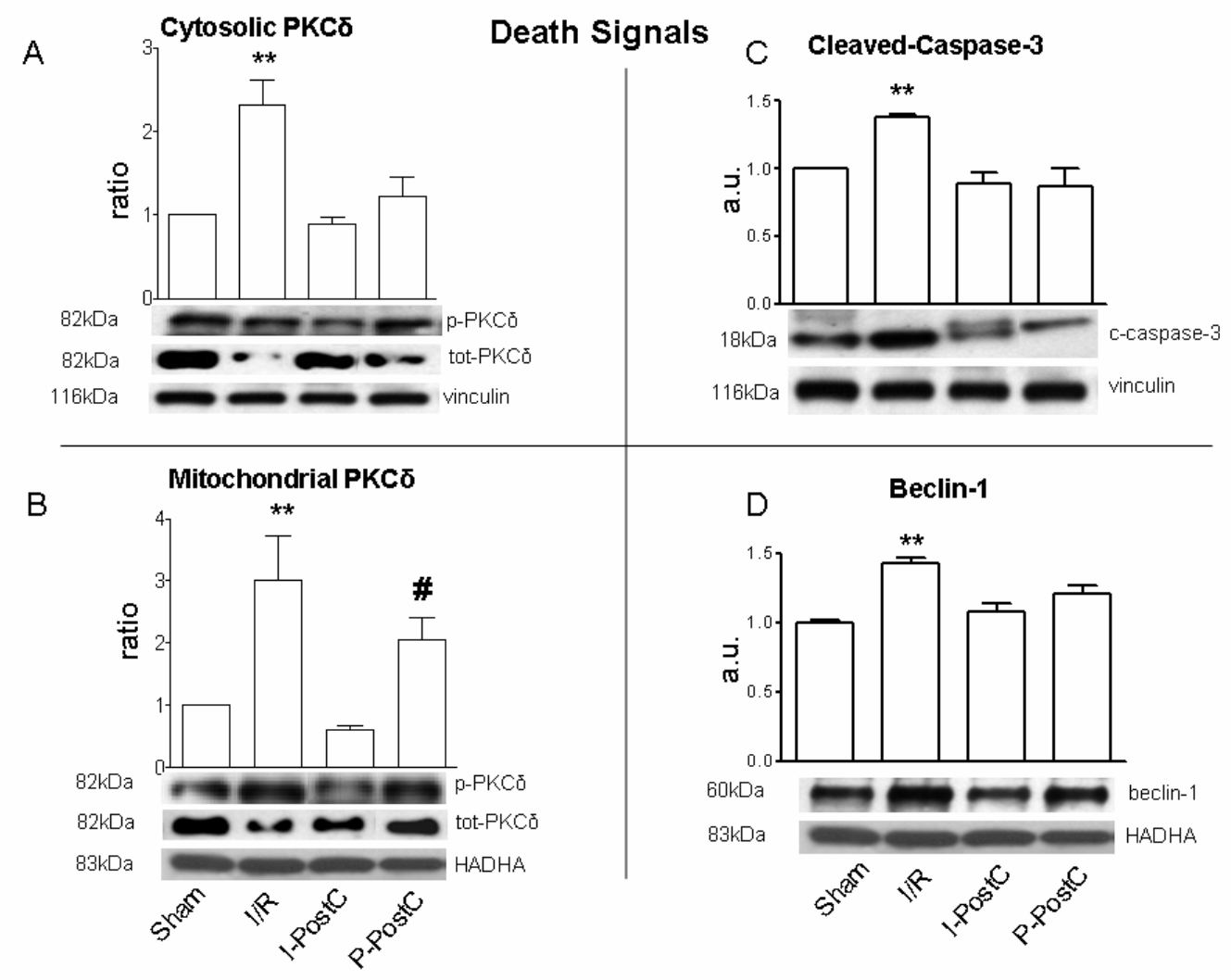

Fig. 8 